\title{
Projeto de Intervenção em Valorização da vida na adolescência
}

\section{Thiago Oliveira Santana}

Psicanalista, Mestre em Educação pela Universidade Federal de Sergipe - UFS e Graduado em Filosofia pela mesma instituição.

\section{Implementação}

\section{Contextualizando}

Adolescência é uma etapa do desenvolvimento do ciclo da vida humana marcado por inúmeras transformações físicas, emocionais e sociais. O sofrimento vivenciado pelo adolescente nesse período pode deixar traços profundos. O comportamento suicida é frequentemente um reflexo de conflitos internos, sentimentos de depressão e ansiedade que acompanhar a profunda reorganização física, psíquica e social que ocorre nesta fase da vida. Muitos comportamentos relacionados a doenças, lesões, morte ou outras consequências negativas se originam na adolescência. O uso de álcool e tabaco, uso de drogas ilícitas, comportamento sexual de risco, agressão, delinquência e outros apresentam maiores taxas de emergência nesta fase da vida. Os comportamentos de automutilação relevantes para a adolescência, geralmente percebidos como uma resposta rebelde, podem realmente estar associados a sentimentos de tristeza ou desesperança. (PAPALIA, 2013).

\section{Estrutura}

1. Público: adolescentes.

2. Objetivo: promover ferramentas vivenciais de valorização de vida em adolescentes.

3. Local: ambiente escolar.

4. Alocação de tempo - Encontro no 1 de Execução: 1h:30min

5. Alocação de tempo - Encontro no 2 de Avaliação: 1h:30min 


\section{Encontro no 1 - Execução}

\section{Procedimento}

a. Etapa 1 - Antecipação: recepção acolhedora dos adolescentes com treinamento do abraço e abertura de escuta.

Será disponibilizado um ponto de apoio com pessoas da equipe do projeto com dois cartazes com as frases: "Abraço grátis" e "Estou disponível a lhe ouvir caso queira conversar".

O intuito é possibilitar acolhimento aos adolescentes no início e no final da intervenção.

b. Etapa 2 - Experimento sobre conformidade social: vivência sobre fatores psicológicos.

Será realizado um experimento comportamental sobre conformidade social inspirado no experimento de Solomon Asch. (LEITE, 2009). O objetivo é sensibilizar os adolescentes sobre a influência do grupo social sobre o comportamento do indivíduo. Será formado um grupo com 8 (oito) participantes entre os adolescentes presentes, sendo 7 (sete) deles instruídos a errar as respostas das perguntas a eles dirigidas, e 1 (um) deles não saberá desta instrução. $O$ intuito é demonstrar como o grupo pode influenciar no julgamento de situação de um único membro isolado.

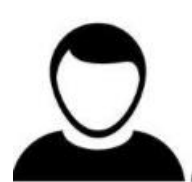

S1

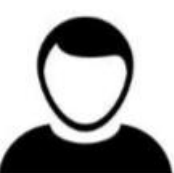

S2

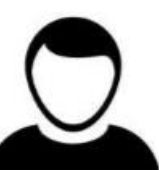

S3

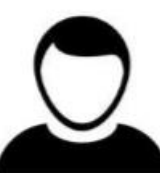

S4

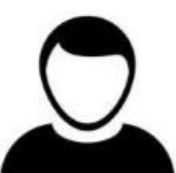

S5

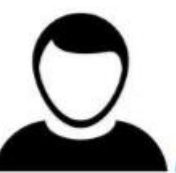

S6

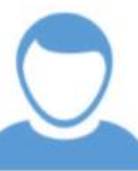

S7

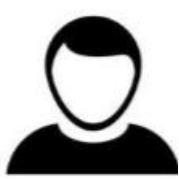

S8 
Será apresentado um cartão com uma linha desenhada e um outro cartão com 3 linhas desenhadas denominadas linhas A, B e C. Uma dessas linhas é do tamanho idêntico a linha do primeiro cartão. Será perguntado aos participantes qual das três linhas tem o mesmo comprimento daquela primeira linha apresentada. Todos os instruídos dirão a mesma resposta errada e o penúltimo a ser questionado será o participante que não sabe da instrução recebida pelos demais.
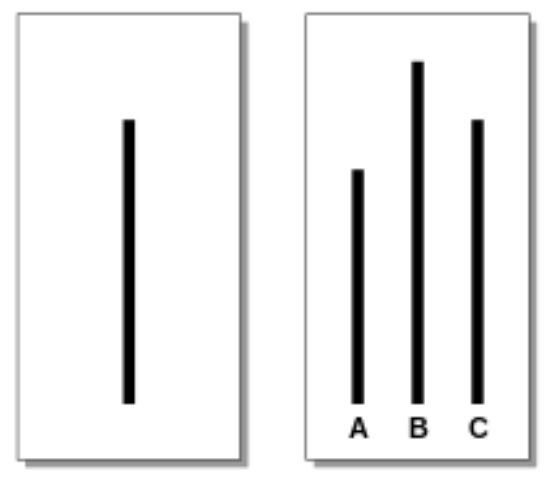

Em um total de dezoito testes, os participantes instruídos irão dar a resposta certa nos seis primeiros, porém nos outros doze testes devem dar respostas idênticas e incorretas.

O objetivo desse método é testar se o participante não instruído dará a mesma resposta que os demais quando todos eles dão a mesma - e incorreta - resposta, observando assim, o fenômeno de conformidade social.

c. Etapa 3 - Roda de conversa: momento reflexivo

Serão divididos vários grupos com 6 (seis) adolescentes e organizados em forma de roda. Cada membro receberá uma figura de celular com uma frase na tela representando fatores do comportamento gerador de risco a vida.

O facilitador iniciará a conversa dando boas-vindas a todos, agradecendo-lhes pela participação. Com os participantes reunidos em roda, introduzirá a temática perguntando: "quem conhece a função do celular?"

Será escolhido um participante para falar o que sentiu, percebeu e pensou sobre a figura de um celular com a frase que Ihe foi entregue. Em seguida, o mesmo adolescente escolhe um outro participante do seu grupo para comentar sobre a próxima frase. 0 próximo participante escolherá o outro a falar até que todos os participantes tenham falado as frases de seu "aparelho". 
O facilitador aquecerá as discussões, unindo as ideias com neutralidade e sem tomar partido, tomando cuidado de não provocar aprofundamentos e com isso gerar sofrimento psíquico.

Em seguida será solicitado a cada participante que produza uma mensagem em "resposta" a primeira mensagem lida no cartão. As novas frases serão lidas pelos participantes e 0 facilitador indagará sobre o processo de construção e suas dificuldades.

Após todos os grupos se pronunciarem, o facilitador convidará os participantes a comporem uma única roda e contarem como foi a experiência de ler as frases de risco a vida nos celulares, como eles se sentiram e quais foram as principais ideias e mensagens mais significativas do cartão e das mensagens em resposta.

Ao final, o facilitador deverá abrir um espaço para comentários gerais e, depois, complementar com as suas impressões articulando os conteúdos e fazendo uma conclusão da roda.

Objetivo é conectar a roda de conversa com o experimento sobre conformidade social realizado na Etapa 2, levando os participantes a refletirem sobre a dificuldade de produzir mensagens de conteúdo de valorização a vida.

Eles serão questionados se essas dificuldades estão associadas ao grande número de mensagens semelhantes que recebemos todos os dias nos celulares, nas redes sociais, nas mídias e suas publicidades.

Abaixo alguns questionamentos norteadores para finalização da roda de conversa:

- O teor das mensagens que recebemos nos celulares, redes sociais, mídias e publicidades valorizam a vida na adolescência?

- Será que estamos reproduzindo mensagens com conteúdo de desvalorização da vida por serem mais numerosas?

- Seriam essas mensagens um dos efeitos do fenômeno de conformidade social vivenciado no cotidiano e por isso a dificuldade em construir frases de valorização a vida?

O facilitador, a partir destes questionamentos, finalizará a roda de conversa promovendo uma reflexão integrativa. 
d. Etapa 4 - Encerramento: acolhimento aos adolescentes que desejam conversar sobre vivências singulares que não puderam ser compartilhadas em grupo e recolhimento das mensagens "respostas" confeccionadas.

Os membros do projeto se organizarão em dupla para acolher o adolescente que deseja conversar de forma reservada sobre alguma experiência privada. A dupla se apresentará e instruirá 0 adolescente que esse diálogo terá alguns minutos. $O$ diálogo deverá ser pautado pelo acolhimento empático, visando integração emocional sem gerar grandes aprofundamentos, e caso necessário, haverá indicação da busca de um psicólogo para o devido acompanhamento.

Outro grupo de membros recolherá as frases "respostas" produzidas pelos participantes sobre valorização da vida. Com as mensagens recolhidas serão confeccionados, sem que os participantes saibam, cartazes em folha cartão tamanho A4 em caligrafia lettering, e devolvidas no Encontro no 2 - Avaliação que será realizado na instituição uma semana depois o encontro $n^{0} 1$.

\section{Encontro nº 2 - Avaliação}

Avaliar o processo de vivência no projeto é tão importante quanto vivenciá-lo. Isso irá ajudar os membros do projeto a perceberem como foi a experiência e os avanços ligados ao tema trabalhado.

A avaliação ocorrerá uma semana depois com os adolescentes e no mesmo local do Encontro no 1 - Execução. Neste novo encontro serão apresentados ao público alvo as frases em cartazes em folha cartão tamanho A4 em caligrafia lettering, escritas por eles sobre valorização da vida na Etapa 3.

Objetivo é causar uma surpresa positiva nos participantes, uma concretização do processo de escuta de cada frase produzida por eles e valorização da produção coletiva realizada no projeto.

Juntos, membros do projeto e os adolescentes, refletirão sobre o encontro no 1 Execução e utilizarão os cartazes com as frases "respostas" para decorar os banheiros, corredores, salas e demais ambientes de convívio social da instituição. 
A essência desse momento será promover uma reflexão sobre comportamentos vividos na adolescência, e desenvolver novas saídas criativas usando recursos que eles mesmos possuem para valorização da vida.

\section{Recursos materiais}

Cartazes, cartões experimento conformidade social, cartões com imagem de celulares e frases confeccionadas em caligrafia lettering, canetas coloridas, marcadores de texto, fita crepe.

\section{Referências bibliográficas}

LEITE, D. M. Estudos em Psicologia. São Paulo: UNESP. 2009

ORGANIZAÇÃO MUNDIAL DA SAÚDE. Prevenção do suicídio: um manual para profissionais da saúde em atenção primária. Genebra, 2000.

PAPALIA, D. E. e FELDMAN, R. D. Desenvolvimento Humano. Porto Alegre: Artmed. 2013. WERLANG, B. G.; BOTEGA, N. J. Comportamento suicida. Porto Alegre: Artmed Editora, 2004. 